\title{
Detection and analysis of volatile organic chemicals in waste water using an electronic nose
}

\author{
E. J. Staples ${ }^{1} \&$ S. Viswanathan ${ }^{2}$ \\ ${ }^{1}$ Electronic Sensor Technology, Newbury Park, USA \\ ${ }^{2}$ National University, La Jolla, USA
}

\begin{abstract}
This paper describes use of a new type of electronic nose, called the zNose ${ }^{\circledR}$ for measurement of volatile organic compounds in water. Based upon ultra-fast gas chromatography, the zNose ${ }^{\circledR}$ is able to perform analytical measurements of volatile organic vapors in near real time with part-per-billion sensitivity. Separation and quantification of the individual chemicals within water samples is performed in seconds. Using a patented solid-state mass-sensitive detector, picogram sensitivity, universal non-polar selectivity, and electronically variable sensitivity is achieved. An integrated vapor pre-concentrator coupled with the electronically variable detector allow the instrument to measure VOC concentrations spanning $6+$ orders of magnitude.

Using the electronic nose an on-site procedure for measuring the concentration of VOCs in water based on headspace analysis is described. Measurement of volatile chemicals in water headspace vapors is correlated with water standards using Henry's Law. Use of this instrument and procedure for aniline and nitrobenzene contaminated water is described. The real time measurement technique has recently been used to measure the concentrations of aniline and nitrobenzene in the Songhua River caused as a result of an explosion at a petrochemical plant in northeastern China. The ease and economics of real time on-site measurements has direct financial benefits.
\end{abstract}

Keywords: VOCs in water, electronic nose, aniline, nitrobenzene. 


\section{Introduction}

Conventional electronic noses, called eNoses, can produce a recognizable response pattern using arrays of dissimilar but not specific chemical sensors [1]. Although electronic noses have interested developers of neural networks and artificial intelligence algorithms for some time, physical sensors have limited performance because of overlapping responses and physical instability. Because eNoses do not separate the individual chemical compounds they cannot identify or quantify the concentration of VOCs in wastewater.

Detection and measurement of VOCs in wastewater poses a difficult challenge because of the sample preparation requirements and the need for analysis by slow chromatographs maintained in laboratory environments. Such analyses are expensive and time consuming. However a new type of electronic nose, called the zNose ${ }^{\circledR}$ is based upon ultra-fast gas chromatography and can provide a cost-effective on-site measurement solution.

\section{Ultra-fast gas chromatograph}

A high-speed chromatography system shown in Figure 1 consists of two sections [2]. One section maintains a constant $3-\mathrm{ccm}$ flow of helium gas passing through a 1-meter length of capillary tubing (column) and impinging onto the surface of a temperature-controlled quartz crystal (Surface Acoustic Wave resonator). Capillary columns are $0.25 \mathrm{~mm}$ I.D. stainless steel tubing with a polysiloxane coating on the inner surface. The column is resistively heated by passing an electrical current through it and temperature is measured by an RTD attached to the column. Direct heating and closed-loop microprocessor control enables linear ramping of the column temperature at rates as high as $20^{\circ} \mathrm{C} /$ second. The other section of the system is used to sample ambient air and consists of a heated inlet and a pump. Linking the two sections is a "loop" trap, which acts as a preconcentrator/adsorber when placed in the air section (sample position) and as an injector when placed in the helium section (inject position). The 'loop' trap is a $3-\mathrm{cm}$ length of resistively heated metal capillary tubing filled with Tenax ${ }^{\circledR}$ adsorbent.

System operation is a two-step process. Ambient air (odor) is first sampled and organic vapors collected (preconcentrated) on the trap. After sampling the trap is switched into the helium section where adsorbed compounds are released as a narrow pulse by rapidly heating the trap to $250^{\circ} \mathrm{C}$. The individual compounds undergo an adsorption interaction as they pass through the capillary column and exit separated in time with characteristic retention times. Retention time is a function of each compounds volatility and adsorption characteristics. In general, lighter and more volatile compounds exit the column first followed by the heavier and less volatile compounds. As they exit the column they are physically adsorbed on the surface of the quartz crystal.

A photograph of the complete portable electronic nose system consisting of a handheld sensor head, support module, and laptop computer is shown in Figure 2. The sensor head contains the gas chromatograph while the support 
module contains a disposable helium tank and a re-chargeable lithium battery. Full portability with over 350 chemical analyses per helium tank and 6-8 hours of battery operation are achieved. A laptop or tablet computer serves as the user interface and contains proprietary chromatography and electronic nose software integrated with Microsoft Office ${ }^{\circledR}$ programs such as Powerpoint, MSWord, and Excel. Wireless connectivity is achieved using a Bluetooth connection.

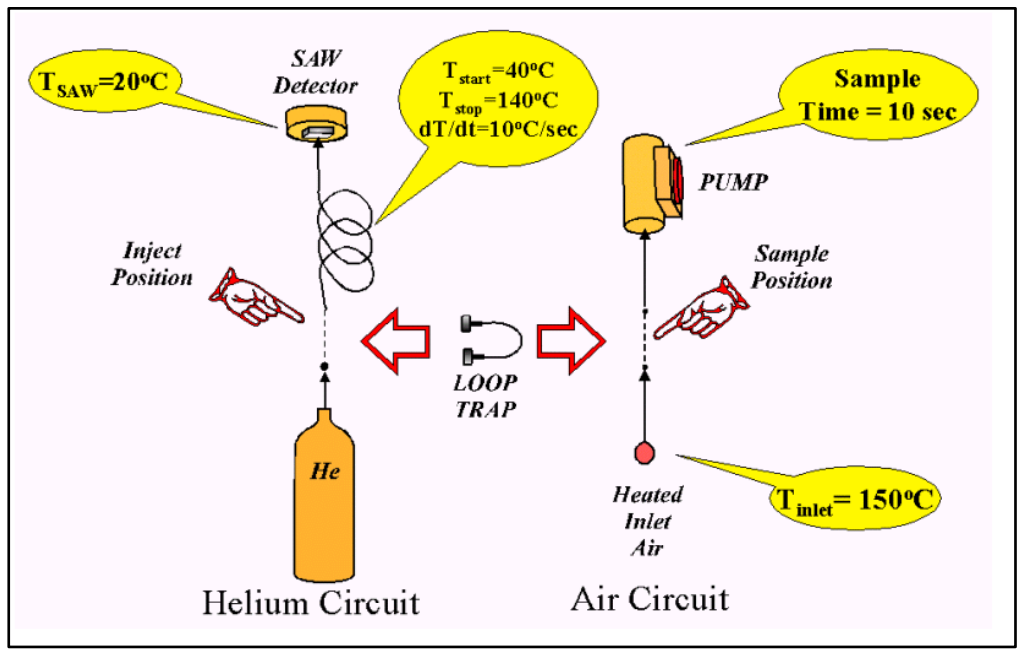

Figure 1: $\quad$ Simplified schematic of ultra-fast gas chromatogaph [2].
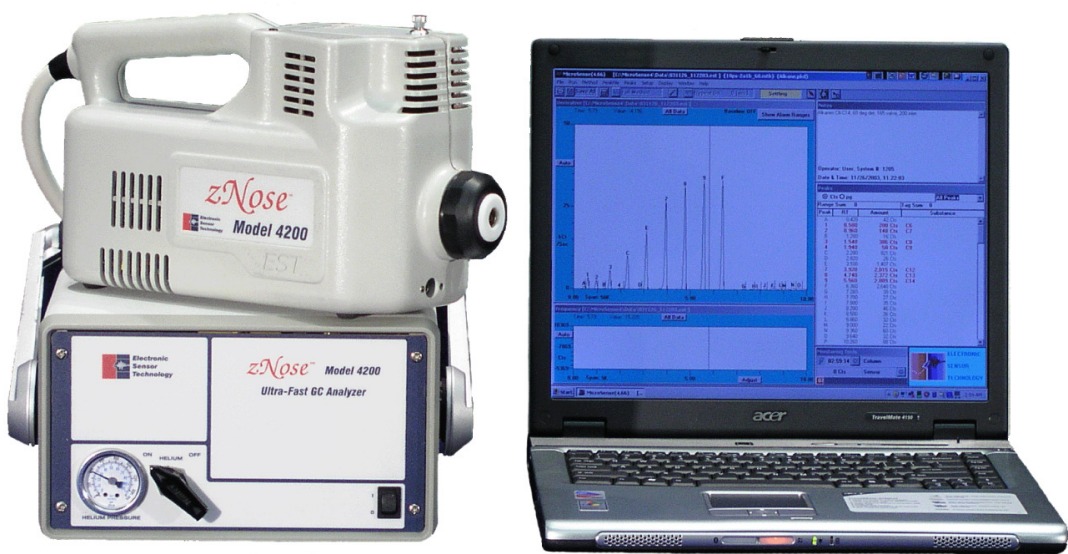

Figure 2: Photograph of electronic nose using ultra-high speed chromatography. 


\section{Surface acoustic wave detector}

Detector response time, sensitivity, and selectivity are key factors in high-speed chromatography. Conventional GC detectors respond to column flux and contain internal 'dead' volume, which produces undesirable broadening of short duration chromatograph peaks [3]. In contrast an integrating type of detector, such as a vibrating quartz crystal, which physically adsorbs compounds as they elute from the GC column will respond quickly and have zero dead volume.

A GC detector for fast chromatography is produced by bonding a piezoelectric quartz crystal $(0.4 \times 0.2 \times 0.01 \mathrm{~mm})$ to a thermoelectric heating and cooling element as shown in Figure 2(a). Photolithographically defined electrodes on the top surface produce standing acoustic waves $(500 \mathrm{MHz})$ which are focused into a small central region approximately $0.25 \mathrm{~mm}$ in diameter. Helium gas from the GC capillary column is directed by a nozzle so as to impinge upon the central region containing the resonant surface acoustic waves as shown in Figure 2(b). Physically adsorbed organics on the crystal surface change the frequency of the resonator by slowing down the surface waves. The change in frequency is proportional to the adsorbed mass on the crystal surface. The thermoelectric element provides the precise control of temperature needed for accurate quantification of vapor concentration. The crystal can be cooled to as low as $0^{\circ} \mathrm{C}$ to increase sensitivity, and heated to as high as $150^{\circ} \mathrm{C}$ to desorb condensed compounds and clean the quartz surface after each analysis.

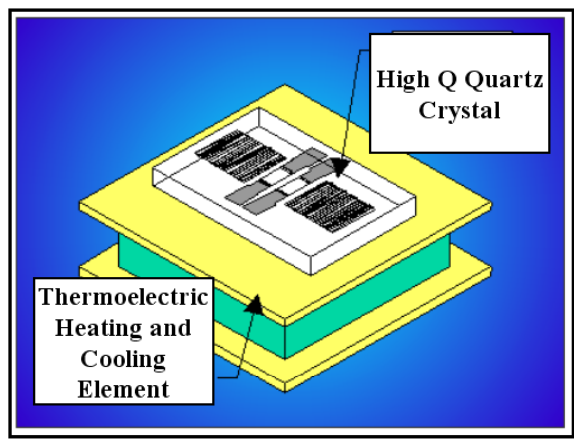

A

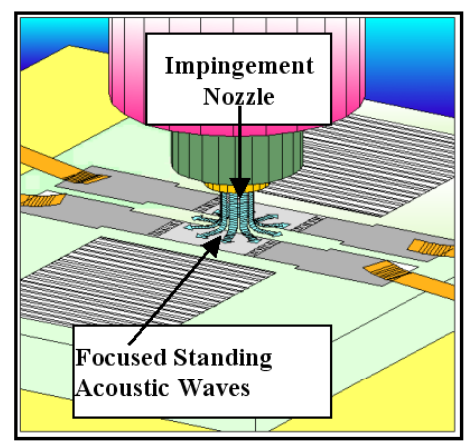

B

Figure 3: GC detector using SAW resonator crystal and thermoelectric heating-cooling element [4].

Because the SAW detector uses purely physical adsorption it is non-specific and frequency changes can be used to quantify the mass of any condensable compound and detection levels are typically three orders of magnitude lower than those reported using coated SAW sensors. The reasons for this increased sensitivity are high crystal frequency and the focusing of resonant acoustic wave energy and adsorbed mass into a small-localized region of the crystal. Minimum detection levels in the frequency domain is directly related to short term frequency stability and uncoated SAW resonators have better stability 
because of higher Q, typically 10,000 at $500 \mathrm{MHz}$. Uncoated quartz resonators also have excellent long-term stability and can operate over a wide temperature range.

Physical adsorption of a chemical vapor is an exponential function of surface temperature and variable sensitivity can be achieved by controlling the crystal temperature with a thermoelectric element [3]. SAW sensor frequency deviation ( $1 \mathrm{~Hz}=1$ count) vs crystal temperature using tetradecane $\left(\mathrm{C}_{14}\right)$ as an example is shown in Figure 4. Sensitivity continues to increase until the compound is totally adsorbed. Total adsorption produces maximum mass sensitivity, typically $10 \mathrm{~Hz} /$ picogram at $500 \mathrm{MHz}$. Once a compound is totally adsorbed it remains on the crystal until the temperature is raised causing it to evaporate from the crystal surface.
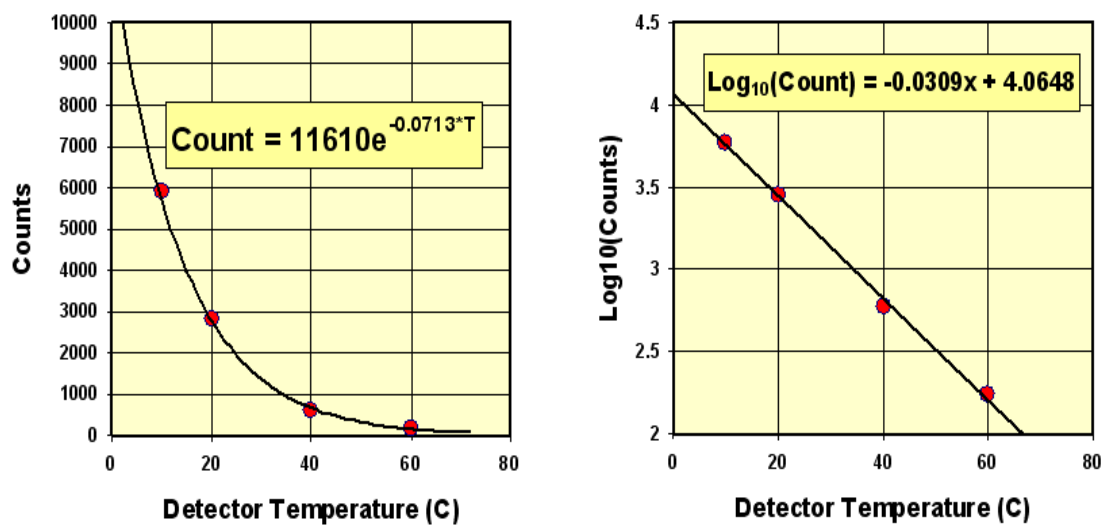

Figure 4: $\quad$ Exponential dependence of SAW detector sensitivity.

\section{Detecting Aniline and Nitrobenzene vapors}

A wide variety of different instrument configurations, called method files, can be created and then selected for measuring the concentration of volatile organic vapors. Method files contain instrument parameters such as sample time, column temperature profile, and detector temperature. Vapor standards are used to calibrate each method and determine system response factors for the method [5]. Response factors for specific compounds are stored in special files called peak files, which are linked to relevant method files.

To illustrate a vapor standard for aniline and nitrobenzene was created by injecting 1229 nanograms of nitrobenzene and $1020 \mathrm{ng}$ of aniline into a 250 milliliter bottle. The concentrations within the bottle were $4.92 \mathrm{ng} / \mathrm{mL}$ (875 ppbv) of nitrobenzene and $4.08 \mathrm{ng} / \mathrm{mL}(1.062 \mathrm{ppmv})$ of aniline. The standard vapors were then sampled with the electronic nose using a sample time of 10 seconds, a detector temperature of $20^{\circ} \mathrm{C}$, and a column temperature profile 
of $40^{\circ} \mathrm{C}$ to $180^{\circ} \mathrm{C}$ at $10^{\circ} \mathrm{C} /$ second. The response is shown in Figure 5. For this method the aniline response factor is 4815 counts/ppmv and for nitrobenzene 10,146 counts/ppmv. The minimum detection level for aniline is approximately 2 ppbv and for nitrobenzene 1 ppbv. Increasing sample time and/or reducing detector temperature can achieve even lower detection levels.

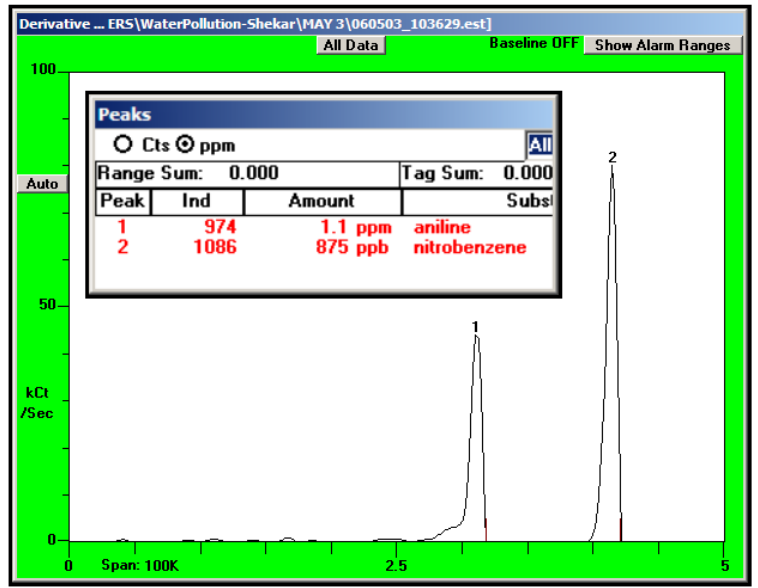

Figure 5: Detection of aniline and nitrobenzene vapors.

\section{Measuring Henry's constant with electronic nose}

Water containing volatile organic compounds will generate headspace vapors containing these same compounds when placed within a sealed container. Compounds partition according to Henry's law and the ratio of air and water concentration in equilibrium defines Henry's constant (dimensionless) for each compound.

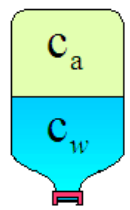

$$
\mathrm{H}_{\mathrm{C}} \equiv \frac{\mathrm{c}_{\mathrm{a}}}{\mathrm{c}_{\mathrm{w}}}
$$

The total mass within the container, $\mathrm{M}_{\mathrm{T}}$, can be expressed in terms of the water concentration, $\mathrm{C}_{\mathrm{W}}$, water volume, $\mathrm{V}_{\mathrm{W}}$, air concentration, $\mathrm{C}_{\mathrm{a}}$, and headspace volume, $\mathrm{V}_{a}$.

$$
\mathrm{M}_{\mathrm{T}}=\mathrm{c}_{\mathrm{w}} \mathrm{v}_{\mathrm{w}}+\mathrm{c}_{\mathrm{a}} \mathrm{v}_{a}
$$


After some algebraic manipulation the air concentration can be expressed as:

$$
\mathrm{c}_{\mathrm{a}}=\frac{\mathrm{H}_{\mathrm{c}} \mathrm{M}_{\mathrm{T}}}{\mathrm{v}_{\mathrm{w}}+\mathrm{H}_{\mathrm{c}} \mathrm{v}_{\mathrm{a}}}
$$

This equation can be used together with headspace measurements to determine Henry's constant for volatile organics in water. Consider the two cases depicted in Figure 6 . In case 1 and bottle of volume, $\mathrm{V}$, is injected with a compound of mass $\mathrm{M}_{\mathrm{T}}$ and the air concentration, $\mathrm{Ca}$, measured with an electronic nose In the second case the bottle is half filled with water and injected with the same compound of mass $\mathrm{M}_{\mathrm{T}}$ and air concentration $\mathrm{C}^{*}{ }_{\mathrm{a}}$. measured.

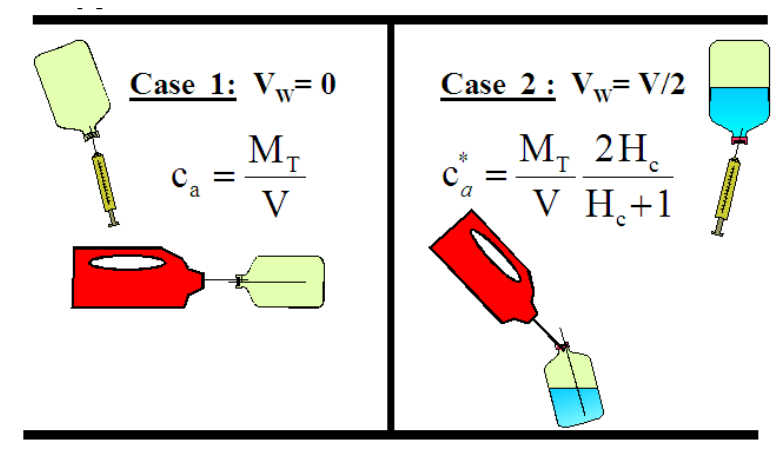

Figure 6: Two cases used to define Henry's constant.

Computing the ratio of the two electronic nose measurements, $\mathrm{R}$,

$$
\mathrm{R} \equiv \frac{\mathrm{c}_{\mathrm{a}}^{*}}{\mathrm{c}_{\mathrm{a}}}=\frac{2 \mathrm{H}_{\mathrm{c}}}{\mathrm{H}_{\mathrm{c}}+1}
$$

Expressing Henry's constant in terms of the two measurements gives

$$
\mathrm{H}_{\mathrm{C}}=\frac{\mathrm{R}}{2-\mathrm{R}}
$$

Using this method Henry's constant for aniline and nitrobenzene was determined and the results are shown in Table 1. 
Table 1: Henry's constants.

\begin{tabular}{|l|c|c|}
\hline & $\mathbf{R}$ & $\mathrm{H}_{\mathrm{c}}$ \\
\hline Aniline & $\mathbf{0 . 0 0 0 1 9 8}$ & $9.91 \mathrm{E}-05$ \\
\hline Nitrobenzene & $\mathbf{0 . 0 0 4 9 5 2}$ & $\mathbf{2 . 4 8 \mathrm { E } - 0 3}$ \\
\hline
\end{tabular}

\section{Water concentration measurements}

To illustrate water concentration measurements, water standards for aniline and nitrobenzene were created by injecting 1229 nanograms of nitrobenzene and $5 \mathrm{mg}$ of aniline into a 125 milliliters of water contained within a 250 milliliter bottle. The water concentrations within the bottle were then $127.9 \mathrm{ng} / \mathrm{mL}$ (127.9 ppb) of nitrobenzene and $40 \mathrm{mg} / \mathrm{mL}$ ( $40 \mathrm{ppm})$ of aniline. The headspace vapors of the water was then sampled with the electronic nose using a sample time of 10 seconds, a detector temperature of $20^{\circ} \mathrm{C}$, and a column temperature profile of $40^{\circ} \mathrm{C}$ to $180^{\circ} \mathrm{C}$ at $10^{\circ} \mathrm{C} /$ second. The chromatogram response is shown in Figure 6. In this case the aniline response expressed in terms of water concentration is 138 counts/ppm and for nitrobenzene 3075 counts $/ \mathrm{ppm}$. The minimum water concentration detection level for aniline is approximately $70 \mathrm{ppb}$ and $3 \mathrm{ppb}$ for nitrobenzene. This result is in agreement with the relative Henry's constant for these compounds expressed in Table 1.

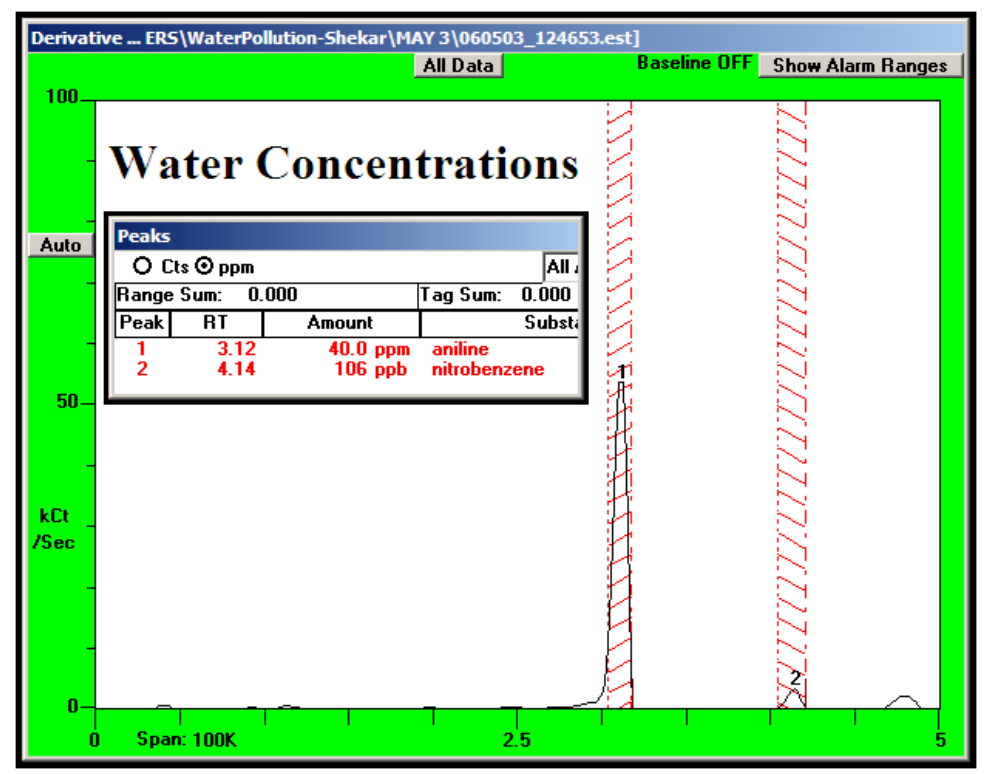

Figure 7: Water headspace measurements. 


\section{Summary}

An electronic nose for on-site measurement of volatile organic compounds in water has been described. Based upon ultra-fast gas chromatography, measurements of volatile organic vapors and their water concentrations in the low part-per-billion range can be achieved on-site. Separation and quantification of the individual chemicals is performed in seconds. Using a solid-state masssensitive detector, picogram sensitivity, universal non-polar selectivity, and electronically variable sensitivity has been achieved. An integrated vapor preconcentrator coupled with the electronically variable detector, allow the instrument to measure VOC concentrations spanning $6+$ orders of magnitude.

The measurement method presented in this paper is based upon water headspace vapor measurements. Using water standards the electronic nose response is easily calibrated so that water concentration is directly displayed. The method has been described using aniline and nitrobenzene contaminated water. The real time measurement method was recently used to measure the concentrations of aniline and nitrobenzene in the Songhua River caused by an explosion at a Petro plant in northeastern China. The ease and economics of real time on-site measurements has direct financial benefits.

\section{References}

[1] Arshak K., Moore E., Lyons GM., Harris J., Clifford., A Review of Gas Sensors employed in electronic nose applications, 2004; 24, 2; ABI/INFORM Global, pp 193-194.

[2] Edward J. Staples and S. Viswanathan, Ultra High Speed and Virtual Chemical Sensors for Detecting Explosives and Chemical Warfare Agents, IEEE sensor journal, volume 5, No 4, August, pp 622-631, 2005.

[3] Watson, G., Staples, E.J., and Viswanathan, S., Development of a Surface Acoustic Wave (SAW) Analyzer for Measurement of Volatile Organic Compound, Environmental Progress, 22 (3), pp 215-226, 2003.

[4] United States Patent Number 5,289,715 was issued to Amerasia Technology Inc. (ATI), Westlake Village, CA on March 1, 1994.

[5] E.J. Staples, T. Matsuda, and S Viswanathan, Real Time Environmental Screening of Air, Water and Soil Matrices Using a novel Field Portable GC/SAW System, Environmental Strategies for the 21st Century, Asia Pacific Conference, Singapore, 8-10 April 1998. 